\title{
Penyampaian Informasi oleh Perawat dalam Persetujuan Tindakan Medis di Rumah Sakit: Permasalahan dan Solusi
}

\author{
Information Delivery by Nurses on Medical Action Consent at Hospital: \\ Problems and Solutions
}

\author{
Yudha Rose Satiti, Aryo Dewanto, Harsono Susilo \\ Program Studi Magister Manajemen Rumah Sakit Fakultas Kedokteran Universitas Brawijaya Malang
}

\begin{abstract}
ABSTRAK
Tuntutan hukum di bidang kesehatan menjadi perhatian utama rumah sakit di Indonesia karena menghabiskan waktu, biaya dan mencemarkan citra rumah sakit. Banyak kasus dugaan malpraktik terjadi karena kurang baiknya penyampaian informasi yang berisiko terhadap tuntutan hukum dan mutu rumah sakit. Penelitian dilakukan dengan cara observasi di ruang rawat inap dan UGD, untuk mengamati proses penyampaian tiap tindakan medis yang dilakukan oleh perawat. Observasi dilakukan berdasarkan PERMENKES Nomor 290/MENKES/PER/III/2008 tentang Persetujuan Tindakan Medis. Untuk mencari akar dari penyebab masalah dilakukan brainstorming dengan peserta 6 orang terdiri dari kepala perawat dan tim mutu dilanjutkan dengan pembuatan fishbone dan teknik "5 Whys" untuk mencari akar masalah. Dari hasil penelitian didapatkan hanya $50 \%$ tindakan yang ada formulir tindakan dilakukan persetujuan informasi medis sebelum tindakan dan $100 \%$ tindakan yang tidak ada formulir, semua persetujuan informasi medis dilakukan sebelum tindakan. Penjelasan tindakan masih sangat rendah berkisar antara 0-30\%. Dari hasil brainstorming didapatkan akar permasalahan adalah pemahaman cara menjelaskan informasi medis rendah, belum ada SK pendelegasian pada perawat untuk menyampaikan informasi medis, sistem pengawasan belum berjalan, SOP kurang jelas atau kurang spesifik, belum ada alat bantu untuk menjelaskan dan perawat tidak tahu cara komunikasi atau penyampaian yang benar. Hasil penentuan alternatif solusi dengan metode McNamara menemukan bahwa alternatif solusi terbaik adalah pembuatan leaflet terkait penjelasan informasi medis dan flyer untuk edukasi pasien.
\end{abstract}

Kata Kunci: Flyer edukasi, Informasi medis, persetujuan tindakan medis

\begin{abstract}
Lawsuit in health is a major concern of hospitals in Indonesia since it spends time, money, and defames the hospital's reputation. Many cases of alleged malpractice occurred because of lack of good information delivery which is risky to lawsuits and the hospital quality. Research was done by observation in inpatient wards and emergency room to observe the process of delivering any medical procedure performed by nurses. Observations based on the Regulation of the Minister of Health No. 290/MENKES/PER/III/2008 on Medical Measures Agreement. To find the root of the problem brainstorming is conducted with 6 participants consisting of the nurse coordinator and the quality assurance team and continued by creating fishbone and " 5 Whys". From the results, medical information consent is done only $50 \%$ of measures from the existing measure form before action and 100\% action which is not on the form, all medical information consent was made before the action. Explanation of action remains very low ranging between 0 to $30 \%$. From the brainstorming results, root of the problem is low understanding on how to explain medical information, no decree delegating nurse to convey medical information, non-working surveillance system, unclear SOP, no explaining aid and nurses do not know how to communicate correctly. Results of alternative solution determination with McNamara method found that the best solution is to invent a leaflet related to medical information explanation and flyer for educating patients.
\end{abstract}

Keywords: Educational flyer, medical information, medical action consent

Jurnal Kedokteran Brawijaya, ol. 28, Suplemen No. 2, 2015; Korespondensi: Yudha Rose Satiti. Program Studi Magister Manajemen Rumah Sakit Fakultas Kedokteran Universitas Brawijaya Malang, Jl. Veteran Malang 65145 Tel. (0341) 569117 Email: roseyudha@yahoo.com 


\section{PENDAHULUAN}

Tuntutan hukum di bidang kesehatan merupakan hal yang menjadi perhatian utama praktisi kesehatan di Indonesia. Kasus yang menyita perhatian adalah kasus Dokter Ayu pada tahun 2013 yang ditahan karena dugaan malpraktik. Aon menyatakan di Amerika pada tahun 2013 terdapat 103.379 tuntutan hukum terhadap rumah sakit dan menghabiskan biaya sebesar 16,6 Milyar Dolar. Jika ditelaah lebih lanjut, banyak kasus yang di duga malpraktik terjadi karena kurang baiknya penyampaian informasi medis (1). Berg berpendapat yang dimaksud dengan tindakan kedokteran atau kedokteran gigi adalah suatu tindakan medis berupa preventif, diagnostik, terapeutik atau rehabilitatif yang dilakukan oleh dokter atau dokter gigi terhadap pasien (1). Setiap tindakan medis yang mengandung risiko cukup besar, mengharuskan adanya persetujuan tertulis yang ditandatangani oleh pasien setelah sebelumnya pasien itu memperoleh informasi yang adekuat tentang perlunya tindakan medis yang bersangkutan serta risiko yang berkaitan dengannya atau biasa disebut dengan informed consent (2).

Pentingnya informed consent bagi dokter dan pasien dalam pelayanan medis karena informed consent merupakan suatu proses komunikasi antara dokter dan pasien untuk menentukan terapi atau penyembuhan yang terbaik dan tepat bagi pasien. Dalam komunikasi tersebut dokter akan menyampaikan informasi atau penjelasan mengenai baik buruknya suatu tindakan medis yang akan dilakukan dan didasarkan informasi atau penjelasan yang disampaikan dokter tersebut maka pasien akan menyampaikan kehendaknya yaitu menerima atau menolak tindakan medis dari dokter. Persetujuan pasien tersebut menjadi dasar pengambilan keputusan medis. Pengambilan keputusan medis akan mudah dilakukan jika segala sesuatu yang berkaitan dengan proses komunikasi sebelum pengambilan keputusan sudah dilakukan dengan baik yaitu menyangkut informasi atau penjelasan yang disampaikan dokter dapat dipahami pasien dan pasien menyatakan persetujuannya.

Rumah Sakit $X$ menerapkan pendelegasian beberapa tindakan medis oleh dokter kepada perawat sesuai dengan Peraturan direktur, sehingga perawat yang memberikan tindakan harus memberikan penjelasan informasi tindakan medis yang akan dilakukan kepada pasien. Hasil observasi awal penyampaian penjelasan informasi tindakan medis oleh perawat di RS $\mathrm{X}$ kepada pasien tampak kurang efektif, dimana masih ada angka ketidaklengkapan form informed consent sebesar 20,3\%. Permasalahan tersebut menyebabkan penurunan mutu dan berpeluang peningkatan risiko tuntutan hukum. Penelitian ini dilakukan untuk mencari penyebab utama tidak efektifnya penerapan penyampaian informasi medis sebagai pertimbangan dan persetujuan medis serta menggalialternatif solusi dan implementasinya.

\section{METODE}

Penelitian dilakukan dengan cara studi dokumen, observasi, dan brainstorming. Studi dokumen dengan melihat laporan informed consent untuk mengetahui kelengkapan informed consent dan melihat SPO informed consent untuk mengetahui tata cara penyampaian informed consent. Observasi dilakukan di ruang rawat inap dan UGD yang dilakukan selama 25 hari dengan pembagian waktu selama 3 jam tiap ruangan. Observasi dengan checklist dilakukan kepada perawat saat akan melakukan tindakan medis, penilaian observasi dengan menggunakan panduan PERMENKES nomor 290/MENKES/PER/2008 antara lain melihat penjelasan mengenai diagnosis, tujuan tindakan, alternatif tindakan, risiko, komplikasi, prognosis dan biaya. Observasi pada tiap tindakan dibatasi sebanyak 4 kali agar terjadi pemerataan pengamatan pada tiap tindakan karena ada tindakan yang sering dilakukan dan ada tindakan yang sangat jarang dilakukan. Brainstorming dilakukan untuk mencari akar penyebab masalah dan alternatif solusi, dengan peserta 6 orang terdiri dari kepala perawat dan tim mutu dilanjutkan dengan menggunakan tehnik " 5 Whys" untuk menentukan akar masalah, pemilihan alternatif solusi dengan metode Mc.Namara kemudian dilakukan skoring, dengan skor tertinggi adalah solusi yang terpilih untuk di implementasikan di RSX.

\section{HASIL}

Observasi di unit-unit RS X menunjukkan bahwa tindakan medis di RS $X$ dikelompokkan menjadi dua yaitu yang dilengkapi dengan form informed consent dan tindakan yang tidak dilengkapi dengan form. Tindakan yang dilengkapi dengan form disepakati oleh RS X sebagai tindakan invasif yang berisiko tinggi, sedangkan yang tidak dilengkapi dengan form merupakan tindakan invasif yang berisiko rendah. Tabel 1 menjelaskan bahwa tindakan terbanyak didapatkan pada pemasangan infus yang lebih sering didapatkan karena hampir semua pasien di UGD dan Rawat Inap dilakukan tindakan tersebut. Tindakan yang sering dilakukan dibatasi hanya 4 tindakan untuk pemerataan terhadap tindakan yang jarang dilakukan. Pemasangan Naso Gastric Tube (NGT) paling sedikit dilakukan karena tidak semua pasien rawat inap dilakukan tindakan tersebut.

Tabel 1. Hasil observasi tindakan dan kelompok

\begin{tabular}{llcc}
\hline No & Tindakan & Kelompok & Jumlah \\
\hline 1 & Pemasangan infus & Form & 4 \\
2 & Skin test & Form & 3 \\
3 & Pemasangan NGT & Form & 1 \\
4 & Pemasangan Kateter & Form & 2 \\
5 & Pelepasan infus & Non form & 3 \\
6 & Pelepasan kateter uretera & Non form & 1 \\
7 & Pelepasan NGT & Non form & - \\
8 & Rawat luka nekrotomi & Non form & - \\
9 & Menjahit luka minor & Non form & 4 \\
10 & Melepas jahitan luka & Non form & - \\
11 & Melepas drainage & Non form & - \\
12 & Melepas tampon & Non form & 2 \\
& Total & & $\mathbf{2 0}$ \\
\hline
\end{tabular}

Hasil observasi menunjukkan bahwa dari 20 tindakan, seluruh persetujuan tindakan secara lisan diberikan oleh pasien sebelum petugas medis melakukan tindakan. Pada tindakan yang membutuhkan form, untuk pembubuhan tanda tangan pasien pada form persetujuan tindakan medis yang menunjukkan bahwa pasien telah setuju dengan tindakan yang diberikan, dari 10 tindakan 50\% dilakukan sebelum tindakan dan $50 \%$ setelah tindakan. Persetujuan dan penandatanganan informed consent sebaiknya dilakukan pada saat pasien belum menjalani terapi pengobatan medis. 
Tabel 2. Hasil observasi penjelasan informasi medis berdasarkan jenis form tindakan

\begin{tabular}{clccccl}
\hline \multirow{2}{*}{ No } & \multirow{2}{*}{ Penjelasan } & \multicolumn{2}{c}{ Non Form } & \multicolumn{2}{c}{ Form } & \multirow{2}{*}{ Analisis } \\
\cline { 3 - 5 } & Dilakukan & Tidak & Dilakukan & Tidak & \\
\hline 1 & Diagnosis & 0 & 10 & 0 & 10 & Tidak dilakukan \\
2 & Tujuan tindakan & 0 & 10 & 2 & 8 & Dilakukan sebanyak 20\% hanya yang ada form \\
3 & Alternatif tindakan & 0 & 10 & 0 & 10 & Tidak dilakukan \\
4 & Risiko dan komplikasi & 0 & 10 & 0 & 10 & Tidak dilakukan \\
5 & Prognosis & 0 & 10 & 0 & 10 & Tidak dilakukan \\
6 & Perkiraan pembiayaan & 0 & 10 & 3 & 3 & Dilakukan sebanyak 30\% hanya yang ada form \\
\hline
\end{tabular}

Tabel 2 menjelaskan bahwa pemberian informasi medis pada tindakan yang dilengkapi dengan form masih sangat rendah bahkan pada tindakan yang tidak dilengkapi dengan form tidak ada penjelasan sama sekali. Berdasarkan data di atas menunjukkan bahwa penyampaian informasi tindakan medis oleh perawat di RS X masih rendah sehingga perlu di tingkatkan lagi. Hasil observasi ditemukan ketidaklengkapan dokumentasi rekam medis berupa pembubuhan tanda tangan yang memberi penjelasan dan saksi, akan tetapi kekurangan tersebut dapat diidentifikasi sebelum pasien pulang sehingga perawat berusaha melengkapinya.

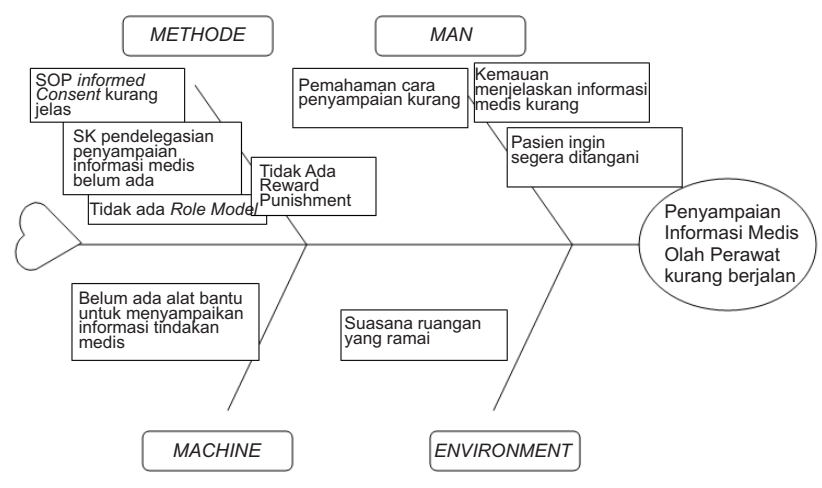

\section{Gambar 1. Fishbone akar masalah penyampaian informasi} medis oleh perawat kurang efektif

Hasil brainstorming yang bertujuan untuk mencari akar masalah ditunjukkan pada diagram fishbone (Gambar 1) dilanjutkan dengan pertanyaan "5 Whys" terhadap cabang sirip ikan. Hasil proses brainstorming dan 5 whys ditemukan 3 akar penyebab masalah yaitu pemahaman cara menjelaskan informasi medis rendah, belum ada SK pendelegasian pada perawat untuk menyampaikan informasi medis, sistem pengawasan belum berjalan, SOP kurang jelas atau kurang spesifik, belum ada alat bantu untuk menjelaskan dan perawat tidak tahu cara komunikasi atau penyampaian yang benar. Identifikasi alternatif solusi dilakukan dengan mengidentifikasi semua kemungkinan solusi yang dapat dilakukan pada tiap level akar masalah, dengan tujuan untuk menghilangkan, mengendalikan dan mendeteksi permasalahan. Metode untuk menemukan alternatif solusi yang dipakai adalah metode tapisan Mc.Namara. Pemilihan alternatif solusi dengan memperhitungkan efektifitas, efisiensi (biaya) dan kemudahan selanjutnya skor tertinggi adalah merupakan solusi yang terpilih. Skor 1 berarti sangat tidak efektif/biaya sangat mahal/sangat sulit dilaksanakan hingga skor 5 sangat efektif/biaya sangat murah/sangat mudah dilaksanakan. Pemberian skor berdasarkan kesepakatan peserta brainstorming.

Tabel 3. Hasil kesepakatan alternatif solusi McNamara

\begin{tabular}{|c|c|c|c|c|c|}
\hline No & Alternatif solusi & Efektifitas & $\begin{array}{l}\text { Efisiensi } \\
\text { (biaya) }\end{array}$ & Kemudahan & Total \\
\hline 1 & $\begin{array}{l}\text { Mengadakan pelatihan } \\
\text { komunikasi cara menyampaikan } \\
\text { informasi tindakan medis }\end{array}$ & 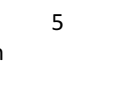 & 2 & 2 & 9 \\
\hline 2 & $\begin{array}{l}\text { Pembuatan leaflet terkait } \\
\text { penjelasan informasi medis dan } \\
\text { flyer untuk edukasi pasien }\end{array}$ & 4 & 4 & 4 & 12 \\
\hline 3 & $\begin{array}{l}\text { Melaksanakan fungsi } \\
\text { pengawasan }\end{array}$ & 4 & 3 & 3 & 10 \\
\hline 4 & $\begin{array}{l}\text { Membuat SK pendelegasian } \\
\text { penyampaian informasi medis } \\
\text { dan merevisi SPO }\end{array}$ & 2 & 4 & 4 & 10 \\
\hline
\end{tabular}

\section{DISKUSI}

Hasil penelitian menunjukkan bahwa persetujuan tindakan secara lisan diberikan oleh pasien sebelum perawat melakukan tindakan, tetapi untuk pembubuhan tanda tangan pasien pada form persetujuan tindakan medis yang menunjukkan persetujuan pasien dan sebagai bukti sah secara hukum hanya $50 \%$ di lakukan sebelum tindakan dan sisanya dilakukan sesudah diberikan tindakan. Pemberian penjelasan informasi medis tidak dilakukan dengan baik sesuai ketentuan permenkes. Para pemberi jasa kesehatan diharuskan untuk memberikan informasi medis baik diminta maupun tidak kepada pasien atau keluarganya (3).

Pemberian persetujuan dan penandatanganan informed consent sebelum pasien mendapatkan pengobatan atau terapi melindungi pihak pemberi jasa dari segi hukum (4). Informasi medis harus dikomunikasikan dengan pasien atau keluarga pasien dengan baik, agar pasien dan keluarga faham dengan kondisi kesehatannya dan sadar dengan keputusannya untuk menerima atau menolak diberikan tindakan medis (5-7).

Dokter harus menjelaskan dan menandatangani dokumentasi informed consent sebelum memasuki ruang terapi. Tujuan dari bentuk tertulis adalah untuk melepaskan instansi rumah sakit dari tanggung jawab hukum. Dalam memberi informasi dokter komprehensif membahas masalah-masalah klien mereka seperti pembayaran, kerahasiaan, keterlibatan pihak ketiga, tujuan pengobatan, protokol, dan durasi (8). Joffe dalam penelitiannya menyatakan bahwa pemberian informasi medis secara jelas dan lengkap membuat pasien merasa puas akan pelayanan (9). Kurangnya penjelasan informasi berakibat pada ketidakpahaman pasien tentang 
kondisinya dan jika terjadi kesalahan pada saat tindakan pasien beranggapan bahwa dirinya adalah korbal malpraktik (10). Pemberian informasi secara jelas dan lengkap sesusai kebutuhan pasien dan keluarga dapat membuat pasien merasa puas, sehingga berpengaruh pada bagusnya mutu suatu RS.

Alasan rendahnya penyampaian sebelum melakukan tindakan antara lain adalah pasien yang banyak, tindakan yang harus dilakukan cepat dan waktu yang lebih lama untuk meminta tanda tangan. Tindakan yang tidak membutuhkan formulir dapat dilakukan $100 \%$ sebelum tindakan karena untuk persetujuan informed consent hanya membutuhkan persetujuan lisan saja. Memberikan informasi yang cukup dan jelas pada pasien dapat membantu pasien dan keluarga dalam mengambil keputusan apakah pasien dan keluarga bersedia untuk menerima pengobatan bahkan mengambil keputusan untuk tidak menerima pengobatan atau menolak (11). Informasi yang diberikan petugas medis secara jelas, lengkap dan disampaikan dengan baik sesuai dengan kondisi pasien, akan membuat pasien merasa lebih puas, dan mudah untuk mengambil keputusan secara bebas (12). Pada pasien yang sudah mendapatkan informasi medis tentang kondisinya dan sudah memahami informasi yang diberikan sebaiknya dilakukan penandatanganan dan dibuat persetujuan secara tertulis, karena hal itu berguna secara hukum (13).

Rahim menyatakan bahwa ada kendala-kendala yang timbul dalam pelaksanaan informed consent antara lain dokter. Dalam sehari dokter melayani 10 sampai 13 pasien, dokter memiliki banyak pasien diruangan lain, kebiasaan dokter untuk mendelegasikan tugasnya kepada tenaga kesehatan dalam hal ini perawat. Tenaga perawat dalam melaksanakan delegasi meminta informed consent kepada pasien atau keluarga tanpa ada beban atau asalasalan karena hal tersebut sudah tugas rutin. Disamping itu beberapa tenaga kesehatan belum sepenuhnya memahami dampak yang timbul bila ada kesalahan, pasien tidak sepenuhnya memahami tentang dunia kesehatan dan budaya pasien yang sering kali menggunakan jasa non medis berupa dukun yang sering dikatakan masyarakat orang pintar (14).

Karena SOP kurang jelas atau kurang spesifik perawat merasa kurang paham cara memberikan informed consent pada pasien. Disamping itu belum ada alat bantu untuk menjelaskan sehingga perawat masih merasa bingung bagaiman cara memberi penjelasan informasi medis pada pasien. Perawat tidak tahu cara komunikasi atau penyampaian yang benar sehingga perawat takut jika salah memberi penjelasan dan tidak bisa menjawab jika ada pertanyaan dari pasien. Downing berpendapat bahwa ada 10 faktor yang menjadi kendala untuk penyampaian informed consent, yaitu kurangnya waktu dari tenaga medis, tenaga medis tidak mengetahui waktu yang tepat untuk menyampaikan informed consent, tenaga medis takut apabila memberikan informasi terlalu banyak, pendapat pasien yang merasa bahwa informed consent

\section{DAFTAR PUSTAKA}

1. Komalawati V. Hukum dan Etika dalam Praktek Dokter. Jakarta: Pustaka Sinar Harapan; 1989.

2. Kementerian Kesehatan Republik Indonesia. PERMENKES Nomor 290/MENKES/PER/III/2008. hanya merupakan formalitas hukum saja untuk keamanan dokter atau rumah sakit, pasien tidak mengetahui bahwa mereka dapat menolak atau menunda tindakan, permasalahan bahasa dan kultur pasien yang sulit menerima informasi, faktor yang berasal dari pasien (IQ, stres, takut), penyampaian informed consent yang kurang baik atau berisi sedikit informasi, pasien salah faham tentang informasi yang diberikan tentang tindakan atau operasi yang akan dilakukan dan kemampuan tenaga medis untuk mengerti keterbatasan pasien (15).

Hasil penentuan alternatif solusi, manajemen perlu membuat leaflet untuk membantu perawat lebih mudah dalam memahami mengenai informasi medis dan teknik menjelaskannya pada pasien. Disamping itu perlu dikembangkan flyer dengan sasaran pasien dan keluarga untuk memberikan edukasi agar pasien dan keluarga lebih sadar tentang informasi dan lebih proaktif untuk menanyakan tentang rencana tindakan yang akan diterima. Dengan upaya tersebut diharapkan terjadi kesinambungan antara upaya perawat untuk menjelaskan informasi medis yang didelegasikan dengan kesediaan pasien dan atau keluarga untuk menerima informasi.

Leaflet merupakan alat informasi yang fleksibel yang memiliki penampilan yang cukup menarik dalam menyampaikan pesan pada konsumen. Media leaflet adalah alat bantu visual untuk meningkatkan efektifitas pemberian informasi (16). Dapat disimpulkan bahwa penggunaan leaflet dan flyer terbukti dapat meningkatkan kepatuhan perawat untuk menjelaskan informasi medis serta dapat mempersingkat waktu pemberian penjelasan informed consent atau informasi medis. Kubba melalui penelitiannya menyatakan bahwa leaflet merupakan media informasi yang berguna, dimana tidak semua orang dapat menyerap informasi medis dengan bagus. Leaflet yang disajikan dengan format yang jelas dan menarik membantu orang untuk lebih cepat memahami informasi medis yang disampaikan oleh petugas (17). Flory melakukan studi literatur untuk mencari efektifitas dari penggunaan media, formulir informed consent yang dimodifikasi dan diskusi dengan pasien secara intensif terhadap pemahaman pasien terhadap informed consent. Hasil yang didapatkan bahwa penggunaan media berpengaruh signifikan terhadap pemahaman pasien terhadap informed consent (18). Media membantu untuk menyampaikan informasi dan sarana komunikasi yang dapat diterima dengan mudah untuk dipahami, dengan desain dan isi pesan yang menarik (19).

Penelitian mengidentifikasi masih lemahnya implementasi informed consent terutama sebelum tindakan karena keterbatasan waktu, pengetahuan, faktor pasien, lemahnya kebijakan termasuk belum adanya SOP serta alat bantu untuk menjelaskan kepada pasien. Solusi pengembangan flyer sebagai alat bantu untuk menjelaskan kepada pasien dipandang sebagai solusi tepat untuk meningkatkan pemahaman sebagai dasar persetujuan tindakan medik yang diberikan.

Jakarta: Kementerian Kesehatan RI; 2008.

3. Soelistyowatie T. Penerapan Hukum Informed Consent terhadap Pelayanan Keluarga Berencana di Rumah Sakit Tugurejo Semarang. Dinamika Kebidanan. 2011;1(1). 
4. Schenk KD, Friedland BA, Sheehy M, Apicella L, and Hewett PC. Making the Cut: Evidence-Based Lessons for Improving the Informed Consent Process for Voluntary Medical Male Circumcision in Swaziland and Zambia. AIDS Education and Prevention. 2014; 26(2): 170-184.

5. Basuki E. Komunikasi antar Petugas Kesehatan. Majalah Kedokteran Indonesia. 2008; 58(9): 340-345.

6. Nur T. Hubungan Kelengkapan Penyampaian Isi Informed Consent Dengan Pemahaman Pasien Bedah Di Rumah Sakit Pertamina Cilacap Tahun 2011. [Skripsi]. Universitas Dian Nusantoro, Semarang. 2014.

7. Sutanto LB, Basuki E, and Bardosono S. Teknik Komunikasi untuk Mendapatkan Informed Consent pada Suatu Penelitian. Majalah Kedokteran Indonesia. 2009; 59(6): 272-276.

8. Fisher $\mathrm{CB}$ and Oransky $\mathrm{M}$. Informed Consent to Psychoterapy: Protecting the Dignity and Respecting the Autonomy of Patients. Journal of Clinical Psychology. 2008; 64(5): 576-588.

9. Joffe S, Cook EF, Cleary PD, Clark JW, and Weeks JC. Quality of Informed Consent in Cancer Clinical Trials: A Cross-Sectional Survey. The Lancet. 2001; 358(9295): 1772-1777.

10. Gutheil TG, Bursztajn $\mathrm{H}$, and Brodsky A. Malpractice Prevention Through The Sharing Of Uncertainty: Informed Consent And The Therapeutic Alliance. The New England Journal of Medicine. 1984; 11(1): 49-51.

11. Redley M, Prince E, Bateman N, et al. The Involvement of Parents in Healthcare Decisions Where Adult Children are at Risk of Lacking Decision-Making Capacity: A Qualitative Study of Treatment Decision In Epilepsy. Journal of Intellectual Disability Research. 2013; 57(6): 531-538.
12. Lynoe N, Sandlund M, Dahlqvist G, and Jacobsson L. Informed Consent: Study of Quality of Information Given to Participants in a Clinical Trial. British Medical Journal. 1991; 303(6803): 610-613.

13. Morrow G, Gootnick J, and Schmale A. A Simple Technique for Increasing Cancer Patients' Knowledge of Informed Consent to Treatment. Cancer. 1978; 42(2): 793-799.

14. Rahim IS. Implementsi Informed Consent di Rumah Sakit Prof. Dr. H. Aloei Saboe. Universitas Negeri Gorontalo, Gorontalo. 2003.

15. Downing BT, Bogoslaw $\mathrm{LH}$, and Juntos $\mathrm{H}$. Effective Patient-Provider Communication Across Language Barriers: A Focus on Methods of Translation. (Online) 2002. http://www.iberistica.unige.it/pdf/brucej_ en.pdf.

16. Supardi S, Sampurno OD, dan Notosiswoyo M. Pengaruh Metode Ceramah dan Media Leaflet terhadap Perilaku Pengobatan Sendiri yang Sesuai dengan Aturan. Bulletin of Health Research. 2002; 30(3): 128-138.

17. Kubba H. An Evidence-Based Patient Information Leaflet about Otitis Media with Effusion. Clinical Performance and Quality Healthcare. 2000; 8(2): 9399.

18. Flory J and Emanuel E. Interventions to Improve Research Participants' Understanding in Informed Consent for Research: A Systematic Review. The Journal of the American Medical Association. 2004; 292(13): 1593-1601.

19. Jones R, Finlay F, Crouch V, and Anderson S. Drug Information Leaflets: Adolescent and Professional Perspectives. Child: Care, Health \& Development. 2000; 26(1): 41-48. 